\title{
MINDS, BRAINS AND LAW: \\ THE CONCEPTUAL FOUNDATIONS OF LAW AND NEUROSCIENCE
}

\author{
By Denis Patterson and Michael S Pardo \\ Oxford: Oxford University Press, 2013. 240 pp. ISBN 978-0-19-981213-4. £55.00.
}

What is the relationship between science and law? In one sense the question seems easy to answeralmost trivial in fact. Law should look to science and learn from it; it should apply it and respect it. Judges, lawyers and law professors act within the realm of science - and when the law disagrees with science, well, then it is bad law. That position seems easy enough to defend, but only in the abstract. It is only when we discuss science and law as if they were monolithic, well established bodies of knowledge that the position is straight forward when in reality these span a wealth of different areas, fields of exploration and more or less well-documented facts. It is as evident that law should respect and assume the law of gravity as it is doubtful that it should apply the latest research on multiple universes in quantum physics. Indeed there is an interesting point here: Law occupies an important position between humanities and the natural sciences in that it needs to interpret scientific findings in a way that makes sense in a universe of concepts like "liability", "responsibility", "agency" and "guilt".

The difficulty of doing this becomes acute when we think about the recent advances in research into human cognition. We need only think about Daniel Kahneman's extensive work on cognitive biases to question whether someone who acts on the basis of a well-established bias is truly acting in a way that implies intent or whether they are instead just the victim of something that we have seen clear evidence of in multiple studies across the globe. Are we responsible for eradicating those biases in our thinking? Should we consciously expect people in certain positions to have received training to avoid them? What, if any, explanatory value do biases have in understanding the question of responsibility? The very fact that they are biases seem to show that they belong in a different category than intentional behaviour at the least.

As cognitive science continues to expand and deepen we will surely see questions like this emerging but there already exists another field where these questions are even more acute. In the emerging field of neuroscience we are now discovering new facts about the brain and these facts are being quickly linked to our mind in a way that implies that they should - need, even - to be relevant to how we think about the law. If science shows that a certain kind of brain damage implies violent behaviour, then surely we cannot hold someone responsible for that behaviour? The defence here, that "my brain made me do it", seems to appeal to a lot of people who are following the evolution of the neurosciences. This, however, is a confused response, despite how understandable and tempting it is.

It is therefore our great fortune to have in Denis Patterson's and Michael S Pardo's new book a thorough analysis of how to think about neuroscience and the law from first principles. The authors of "Minds, Brains and the Law: The Conceptual Foundations of Law and Neuroscience" set out to explore the intersection of neuroscience and law but in doing so achieve much more than just that. The entire work is an, often brilliant, exercise in limiting the claims that scientific findings can lead to in legal reasoning.

The key to understanding these limits lies in understanding the ways in which we end up making mistakes. When a neuroscientist speaks of the "brain deciding something" they are making a series of assumptions about the relationship between the brain and the practice of "deciding" that simply 
are not possible to establish. The authors sum this up as a special kind of fallacy that often occurs in discussing neuroscience and law: The mereological fallacy.

Their work on this fallacy falls into the category of ideas that should be imparted to all law students early on, as the development of all kinds of cognitive science, artificial intelligence and neuroscience will make this principle even more important in the future. Somewhat simplified, the mereological fallacy consists in believing that a part is able to stand for the whole. When we say "the brain thinks" we are blatantly ignoring the fact that we use the word to think only about human beings and even then only as a concept that encompasses a whole pattern of behaviours, utterances and observations. A brain is capable of none of those and to mistake the brain - a part of the person - for the whole and to assume that it thinks is, in one sense, just demonstrating a lack of understanding of the phrase "to think". The same, arguably, could be applied to those that say that an algorithm thinks or, more broadly, that any other abstract system is thinking. Again, we could argue that is not possible as only that which behaves as a human being and which acts like one can be said to think.

This line of thinking, based at least in part on Wittgenstein's analysis of the philosophy of psychology, is an important corrective for the assumption that concepts associated with human agency can easily be applied to brains, machines or parts of people.

There is an interesting possibility here which is one that it would be interesting to see the authors explore in another context; that maybe the law is a lot like thinking. Wittgenstein notes that our use of cognitive concepts often is conditioned on what he called an attitude to a soul - a sense that the whole being is conscious and capable of the many different forms of psychological action that we can describe in our language. It is not impossible to extend, or experiment with extending, this idea to law. Maybe the entire conceptual language game of the law can only be used where we have that same attitude to a soul and, hence, all the questions about brains and machines would be simply misplaced questions that show a certain incompetence vis-à-vis the set of language games involved.

That may also however be taking things too far. The authors of "Minds, Brains and the Law" are actually much more restrained and correspondingly much more rigorous in their approach. They admit that there may well be a set of neuroscientific facts that should be admitted as proof of innocence or guilt and that there are no simple demarcation lines available to us as we study the emerging field of a science to try to incorporate its results into law. This in fact is a valuable lesson from the book. Rather than looking to stake out a sovereign territory for the law and relegating other sciences to their own domain the authors work very hard to find the conditions under which scientific fact can be applied to legal reasoning. Herein lies a methodological recommendation that is of great value: We should work very hard to understand how we qualify scientific progress for inclusion in the law and to be explicitly clear when we are making assumptions and drawing conclusions that are simply the results of conceptual confusion or empirical inexactitude (as in the case of fMRI-studies).

To a certain extent this is also the only possible criticism that can be directed at the authors. They spend the majority of their work showing when conclusions are being drawn that rely on conceptual confusion or incomplete empirical analysis - something that is, of course, beneficial to anyone interested in deconstructing the claims that some think neuroscience makes on the law - but less time is spent defining the conditions under which the authors would allow neuroscientific facts to actually matter. The risk is that the authors will be accused - I think unfairly - of raising an impenetrable wall between law and neuroscience based on a combination of conceptual exceptionalism (that all concepts in law should disallow the use of neuroscientific findings as the mereological fallacy applies to all attempts to use neuroscience in law) and epistemological absolutism (that no instrument can ever be used to establish a fact usable in law as the concepts in 
law are not measurable and therefore no relationship between a physical process and a legal concept can logically be established). Neither of these accusations seem right but it is foreseeable that a frustrated neuroscientist could make both. In order to avoid this it seems that it would be interesting to have spent the last chapter outlining methods, experimental designs, findings and research programs that could really have led to neuroscientific discoveries applicable in law without invoking the weaknesses discussed.

It may also be possible that there is, in fact, a conceptual gap here that cannot be filled. If so, we should try to outline it very clearly. In that case what the authors have done is less to establish the conceptual foundations of a field and more to introduce a critical discussion to underpin all future attempts to establish one.

As a final remark: It is clear that the brain is the next frontier for publicly funded research, both in the US and in Europe. We will see an explosion of neuroscience, of neuromodelling and of neurobased models of artificial intelligence in the next thirty years and more. Their results will necessarily influence other sciences and disciplines and as this happens we are very lucky to have such a thoughtful work to help us think through the boundaries and limits of scientific discoveries in the law.

Nicklas Lundblad

Adjunct professor of innovation at the Royal Institute of Technology, Sr director \& head of public policy and government relations for Europe, Google Inc

All views solely the author's.

DOI: $10.2966 /$ scrip.120115.75 the terms and conditions. 